ACCEPTED MANUSCRIPT

\title{
Advancing energy poverty measurement for SDG7
}

To cite this article before publication: Shonali Pachauri et al 2020 Prog. Energy in press https://doi.org/10.1088/2516-1083/aba890

\section{Manuscript version: Accepted Manuscript}

Accepted Manuscript is "the version of the article accepted for publication including all changes made as a result of the peer review process, and which may also include the addition to the article by IOP Publishing of a header, an article ID, a cover sheet and/or an 'Accepted Manuscript' watermark, but excluding any other editing, typesetting or other changes made by IOP Publishing and/or its licensors"

This Accepted Manuscript is @ 2020 IOP Publishing Ltd.

During the embargo period (the 12 month period from the publication of the Version of Record of this article), the Accepted Manuscript is fully protected by copyright and cannot be reused or reposted elsewhere.

As the Version of Record of this article is going to be / has been published on a subscription basis, this Accepted Manuscript is available for reuse under a CC BY-NC-ND 3.0 licence after the 12 month embargo period.

After the embargo period, everyone is permitted to use copy and redistribute this article for non-commercial purposes only, provided that they adhere to all the terms of the licence https://creativecommons.org/licences/by-nc-nd/3.0

Although reasonable endeavours have been taken to obtain all necessary permissions from third parties to include their copyrighted content within this article, their full citation and copyright line may not be present in this Accepted Manuscript version. Before using any content from this article, please refer to the Version of Record on IOPscience once published for full citation and copyright details, as permissions will likely be required. All third party content is fully copyright protected, unless specifically stated otherwise in the figure caption in the Version of Record.

View the article online for updates and enhancements. 


\section{$1 \quad$ Advancing Energy Poverty Measurement for SDG7}

2

$3 \quad{ }^{1}$ International Institute for Applied Systems Analysis, Laxenburg, Austria.

$4 \quad{ }^{2}$ School of the Environment, Yale University

6 Abstract

7 Existing indicators used to track progress towards achieving target 7.1 of the Sustainable

8 Development Goals (SDGs) narrowly interpret energy poverty as a lack of connections. Recently

9 proposed measurement frameworks are more multidimensional, but complex and conceptually

10 muddled. We propose an alternative framework that simplifies and distinguishes two conceptually

\section{Introduction}

17 The United Nations' Sustainable Development Goal (SDG) 7.1 aims to end energy poverty globally by 2030 (1). Providing energy access universally is seen as a means of ending energy poverty and has been endorsed as a normative goal that is important for sustainable development. However, what 'access' means, what dimensions it comprises, and with what frameworks and indicators it should be measured are still being debated. Currently, two binary indicators are recommended to track Target 7.1 - Indicator 7.1.1: Proportion of population with access to electricity, and Indicator 7.1.2: Proportion 
measure, these indicators have several shortcomings. Most importantly, they tend to overestimate access as they fail to account for the quality of supply and user circumstances that determine real utilization of energy services (2).

Approaches to understanding energy poverty and measuring energy access have evolved over the last couple of decades with growing understanding of how different attributes of energy supply and aspects of household vulnerability matter for which energy services are utilized $(3-10)$. Recent efforts have built off theoretical contributions on concepts of human capabilities and justice $(10,11)$, such as those of Amartya Sen and Rawls $(12,13)$. Most recent contributions, while differing in detail, emphasize the need to move beyond a binary formulation of access that focuses on connections alone to bring greater granularity to the concept. A key motivation to increase granularity is to better reveal injustices in energy provisioning and access that binary quantitative indícators alone might obfuscate (14). Newer conceptualizations emphasize three critical aspects. First that access is multidimensional, and that issues of affordability, reliability and quality of energy services are critical. Second, that there is a need to distinguish between key services or end-uses, at a minimum, between energy for cooking, lighting and other household uses. Third, there is also increasing awareness and agreement that energy access should go beyond a minimum required to meet basic energy services in the home and extend to energy for productive purposes and community services or decent living standards defined more broadly (15-18). In other words, access should be viewed as more of a continuum. Recent reviews of energy access and energy poverty metrics highlight the strengths and weaknesses of alternative approaches and the challenges with applying these in different contexts (19-25).

The World Bank, acting on its mandate to monitor achievements towards SDG 7, has proposed a new Multi-Tier Framework (MTF) as a multi-level, multidimensional measurement framework to measure energy access (26). While the MTF is a significant enhancement to the earlier binary formulations of energy access, we argue that it is now too complex and conceptually muddled to track access at a global scale. It can be further improved by disaggregating and simplifying two conceptually distinct 

aspects of energy access - energy supply conditions, and the status of household energy poverty that require monitoring of different entities, namely utilities or energy providers and households respectively. Different policies may also be needed to either redress deficiencies in service provision or provide support to households. The simplifications we suggest make monitoring simpler and make transparent the links to energy access and poverty. Our modifications also simplify and reduce data requirements. Data are currently not available at a global scale to apply the MTF comprehensively. While this is also the case for our alternative framework, the coverage of surveys with adequate data is greater. Furthermore, as we discuss later, the World Bank (WB) and the World Health Organization (WHO) have recently coordinated the development of a set of new household energy survey questions that will cover all the data requirements of our framework. These standardized set of questions, related to household cooking, heating, and lighting, are recommended for inclusion in national surveys to monitor SDG 7 and track progress. To facilitate inclusion in standard existing surveys, three versions of the harmonized set of questions to align with common national surveys like UNICEF's Multiple Indicator Cluster Surveys (MICS) and USAID's Demographic and Health Surveys (DHS) and the World Bank's Living Standards Measurements Surveys (LSMS) have been made available for inclusion (27). The inclusion of these sets of questions in existing surveys along with ongoing data collection efforts through rollout of MTF surveys should make consistent and comparable monitoring of household energy use patterns across time and populations possible in the next few years. Currently, MTF surveys for 15 countries with the largest electricity access deficit are planned and being administered.

Applications of the MTF to actual regional or national contexts have been quite limited so far, but literature critiquing the approach is already emerging $(7,20,21,28)$. The critiques suggest that the MTF is too complex for global trackjng purposes and too prescriptive to gain acceptance in diverse national settings to guide policy and planning (23). Other key criticisms leveled against the MTF concern the choice of dimensions and attributes selected to measure aspects of energy poverty, the number of tiers or levels these dimensions are distinguished across, and thresholds chosen to distinguish performance among tiers or levels $(7,28,29)$. In particular, the metrics used to capture some 
dimensions are considered inadequate. For instance, the MTF risk indicator was considered inadequate to capture the common energy risk factors related to burns and fires, especially common in crowded urban informal settings in the South African context. In addition, research shows that affordability in South Africa is better measured by a combination of both subjective and objective measures than the single budget share based measure defined in the MTF (28). There is also a lack of consensus of acceptable levels of service quality in defining specific thresholds for different contexts. Our refinements allay some of these concerns.

Here we first present an alternative framework for global tracking of energy access, embedded within a discussion of key conceptual challenges and limitations inherent in the MTF. In doing so, we have two objectives: first, to make more explicit the normative foundation that underlies the goal of energy access and frameworks and indicators used to measure it; and second, to simplify the MTF and thereby balance the need for accuracy of measurement with that of ease and transparency in facilitating wide adoption. We then compare this alternative framework to the MTF by applying both frameworks to household survey data from Ethiopia, India, and Rwanda. We restrict our comparison to household electricity access alone, though the approach could be extended to other energy services and enduses. We show that the MTF underestimates the heterogeneity in the affordability and type of energy services to which poor people have access, and, as a result, underestimates energy poverty. We conclude with some insights on the applicability and usefulness of the frameworks and recommend enhancements to existing surveys and data collection efforts to better capture indicators of interest in such measurement frameworks.

\section{Developing a simple yet comprehensive energy poverty}

\section{measurement framework}

\subsection{Defining tiers of access along an energy 'service' ladder}

The MTF framework includes household electricity consumption as one dimension of electricity

99 access, wherein higher amounts put households in higher tiers. As a guide, the framework provides 
sample groups of appliances that are reflective of different tiers of electricity use, but these are largely defined in terms of rated capacity, not services. The implicit principle behind this framework, presumably, is that more energy use implies a higher level of welfare. However, the amount of energy used as a proxy for welfare from energy services is crude, both in principle and in practice. In principle, energy has no inherent value, but it is instrumental to obtain certain services that do have inherent value to human wellbeing, such as heating or cooling a home to comfortable levels or watching television for entertainment. Thus, tiers ought to be defined explicitly with reference to these services, rather than in terms of a quantum of energy. The same quantity of energy may offer different levels and quality of these services also depending on many technical factors associated with the delivery of the service, such as the efficiency of appliances and household structural conditions. Thus, two households may enjoy very different types of service and still be accorded the same energy poverty status based on their similar energy consumption.

Another concern with the existing tier structure of appliance energy use is that it offers no guidance for an aspirational standard. Although the tiers are intended to represent improvements in service conditions, the principles on the basis of which such an improvement is measured is absent. Households transition up an energy service ladder, acquiring new electrical appliances associated with additional services, as they become more affluent. Some recent literature has alluded to this transition as "energy mobility" (30). If the SDG were to be expanded to include these additional dimensions of access, targets would have to be specified for each, for instance which services should be included in an aspirational basket. A few measures of energy poverty offer such a threshold but encompass a wide range of services with limited justification. The 'minimum energy poverty threshold' (4) includes the level of energy demand required for subsistence, which the authors interpret and empirically estimate as a minimum level for lighting, cooking, and heating. Other measures implicitly consider electric energy for lighting, small appliances and clean stoves and fuels for cooking as a level of energy services

124 that must be provided universally $(31,32)$. In a few cases, additional services such as refrigeration or 125 space cooling, information and communication, as well as energy (mechanical) for productive 
purposes are included in such measures $(3,5,6,33)$. However, these proposals lack normative support

127 for their assumptions, particularly in terms of the role of these services in enhancing human wellbeing.

128 Building on a mix of sources from empirical testing, measurements and literature, Practical Action

129 provides a broad discussion of minimum energy service needs and thresholds, including those for

130 household needs, productive ends and community services (33). Another approach also lends support

131 for many of these services as necessary means to achieve basic wellbeing (characterized as a/decent

132 living standard'), including good health and social affiliation (15). On this basis, in order to escape

133 poverty and achieve basic wellbeing, households should be entitled to cook without dangerous indoor

134 air pollution, store food in refrigerators, afford comfortable temperature/humidity conditions in the

135 home, and have the devices and infrastructure to access broadcast media. This rationale, that energy

136 access is a means of improving wellbeing, underlies the tier definitions we propose (Figure 1), as

137 discussed further below. Geographic and cultural conditions may require these standards to be operationalized somewhat differently in terms of the actual appliances and affordability criteria they entail.

\subsection{Focusing on additional critical dimensions of access}

\section{$142 \quad$ 2.2.1 Reliability/Availability}

143 Reliability, or regular availability of supply, enhances the economic benefits from electricity access,

144 and consequently well-being. Recent evidence from rural India also suggests that daily supply duration

145 is the best predictor of satisfaction with electricity supply $(29,34-37)$. The World Bank's MTF defines

146 reliability in terms of duration of supply, distinguishing between hours during the day and evening

147 hours of supply, and frequency of outages or disruptions. The rationale for monitoring hours of use in

148 the day and in the evening separately, while sound, has not found consensus in implementation due

149 to the variation in socially and politically acceptable levels of supply disruption in different contexts

$150(28,29)$. We suggest for simplicity to measure total daily availability. To decide on how many tiers or

151 thresholds it is useful to distinguish between reliability tiers, we conducted a Theil decomposition 
analysis on our three household surveys that include data on average supply availability. The decomposition analysis is used to calculate the share of variability that is explained by variation within and between tiers (see Supplementary Table 1). The greater the between-group share of variability, the less the motivation to define more tiers. The analysis reveals that the between-group share dominates the within group share for anywhere from two to five tiers, but there are diminishing returns with increasing tiers. Based on this, we concluded that distinguishing three tiers is a reasonable compromise between accuracy and simplicity, the latter being important for successful implementation. The distinction we propose is between $<8$ hours, $8-16$ hours and $>16$ hours of daily availability. This simplifies the more complex five tier differentiation of hours of availability and outage frequency defined in the MTF. At the same time, we expect that it will sufficiently capture observed variations in energy service utilization based on daily and seasonal supply profiles of a range of grid and decentralized intermittent energy supply provision options. It is likely that having electricity available for less than 8 hours, particularly if not predictable, can impede households' ability to enjoy 'decent' level of energy services, such as refrigeration or air conditioning, when required.

\subsubsection{Affordability}

168 The World Bank's MTF defines a single threshold for affordability, at 5 percent of household income, 169 for a standard consumption package of $365 \mathrm{kWh}$ per year. Taking cooking and electricity together, this 170 implies households spending more than 10 percent on household energy would be considered energy poor. Choosing a suitable affordability threshold for energy services in isolation is an ill-posed problem, considering that its effect on households' purchasing power depends on the costs of other basic necessities. Indeed, using a fixed proportion of income measure has been strongly critiqued in the European context (38). Further, for households in poor agrarian settings and engaged in more informal activities, asset or wealth indices could serve as a better base from which to assess relative affordability. At a global level, the intention of such a threshold is to carve out an adequate, but maximum, amount of financial space for energy services and thereby limit the financial burden on 
other necessities. However, energy metrics also measure relative progress within and across countries, to inform policies that provide support to households. In this regard, a single threshold may not provide the degree of information needed to prioritize efforts if a population is considerably large and diverse. Indeed, we show below that for the countries we consider, there are a non-trivial share of the poor who pay over 5 percent, and even above 10 percent just on electricity. We suggest that at least one more tier is needed to reveal the heterogeneity in financial conditions.

Another important consideration in keeping with the focus on energy services is that the costs included in an affordability measure should include the appliance costs as well, and not just expenditures on energy. We show later that this shifts a significant number of people downward in the tiers. Capturing the total cost of energy services, including that of appliances and supply equipment or connections, is particularly critical given increasing efforts now to provide electricity access through unregulated decentralized systems.

\subsubsection{Cost of supply}

We distinguish cost of supply, a supply dimension, as distinct from affordability, an energy poverty dimension. This is because cost of supply, both for connections and regular use, reflect service providers' efficiency, subsidies from government and the related political economy of the sector. People who cannot afford the cost of available energy are likely to remain excluded from access. Cost of supply can vary spatially or for different categories of customers depending on geographic factors (distance from generation or supply centers) or pricing policies (block tariff design, variations in taxes and subsidies), and may even be influenced by corruption and misappropriation of rents/ revenues. This can also serve as an indicator of the financial health of utilities and energy suppliers. Information on cost of supply (including fixed and variable charges) should ideally be collected from energy suppliers. Tiers for this dimension could then be defined as deviations from an average value, with thresholds defined as plus or minus a multiple of the standard deviation around the mean. One way 
to approach this indicator is to use national benchmarks for utilities and service providers based on best practices within countries or regions. In the application presented later for Ethiopia, India and Rwanda, we do not operationalize this indicator, as data for this was not consistently available across the three nations.

\subsection{Energy supply as distinct from household energy poverty}

The MTF conflates dimensions that describe aspects of energy delivery and supply with those that are related to user circumstances and preferences (21). The hours of availability, the voltage/frequency of electricity, costs of connection and the electricity tariff define supply conditions. On the other hand, lack of insulation is a property of the household's energy poverty. The per unit cost of electricity and building insulation, along with other factors, determine heating or cooling costs, and in turn the expenditure share of energy for a household.

Despite their relatedness, the risk of putting these dimensions together and aggregating them into a composite metric is manifold. Most obvious is that their aggregation masks the relative contributions of each. The deeper concern is that it masks where to target efforts of reform. Supply conditions should be monitored and ranked separately to target utilities and service providers for reform. Household conditions need to be considered more broadly in the context of poverty, so as design appropriate social support policies for housing or efficient appliance purchase. Because of this, even

221 if the multiple dimensions were used as a dashboard (and not combined into a single indicator) their delineation into these two facets is useful to provide conceptual clarity and guide policy better.

\subsection{Building an alternative measurement framework}

225 Based on the above critique, we suggest simple revisions to the MTF that reduces the number of tiers

226 from five to three, aligns these tiers more closely with a hierarchy of energy services, and groups these 
dimensions into supply-related and energy poverty-related ones (Figure 1). For global tracking purposes, we argue that at a minimum, the energy supply measure should include reliability and cost of service, and the energy poverty measure should include affordability and energy services. These attributes also capture those explicitly stated in Target 7.1 of the SDGs that were globally agreed on in September 2015.

As discussed above, in distinguishing tiers by energy services, we define a lower/tier (Minimal) as a level of energy for basic safety and security, or 'energy subsistence'; a middle tier (Decent) as a level that affords a decent living standard; and the highest tier (Affluent) as reflecting discretionary energy use. In addition to capturing normative contributions of life quality, these tiers also reflect the order in which people tend to acquire electric appliances in the world (39). Energy subsistence includes lighting, fans for a minimal level of space conditioning required in much of the global south, and cell phone charging. Although cell phone charging may not be considered as fundamental, people tend to acquire it prior to any other appliance, and are often offered this in conjunction with lighting. 'Decent' energy services additionally include refrigerators and $A C$ for food storage and space conditioning respectively, and TV or similar device to access broadcast media, which is important for social wellbeing. We include $A C$ in the decent tier, because although it is typically a luxury item in practice, there are studies showing that AC would be necessary to avoid heat stress-related health impairments in large parts of the world (40-42). The risk that wealthy households in moderate climates that own ACs as a convenience would be classified in this tier is low, considering that such households likely also own other appliances that would put them in the 'affluent' category. Although washing is also a basic need, it can and often is met through communal washing facilities. Individual household ownership of washing machines is more of a luxury, typically lagging televisions and refrigerators in ownership rates. 'affluent' level of service includes all other appliances, including microwaves, computers and electronic gadgets (39). We suggest that households should be assigned to the highest tier into which any of their appliances fall. That is, a household would fall in the 'decent' category only if it owns either a refrigerator, TV (or equivalent device) or AC, but none of the appliances in the 'Affluent' tier. 
253 We define two thresholds (and therefore three tiers) for affordability, to further distinguish

254 households that pay over 10 percent of their total expenditure on electricity from those who pay over

2555 percent. Similarly, we define two thresholds and three tiers for reliability or regular availability, to

256 distinguish households for whom the duration of supply is less than 8 hours a day from those that can

257 increasingly utilize additional appliances and energy services.

258 We now apply and compare this simplified framework to the MTF for the case of /ndia, Ethiopia and

259 Rwanda to illustrate that the MTF masks significant heterogeneity among the poor, which this new 260 framework better reveals.

INSERT Figure 1: A simplified alternative framework compared to the Multi-Tier Framework for energy access measurement.

\section{Testing the alternative framework tomeasure access}

\subsection{Data and methods}

To apply the MTF and our alternative framework (AF) for energy poverty measurement in Ethiopia,

India and Rwanda we use micro-data from existing national household surveys. For Ethiopia and

Rwanda, we use surveys that were recently conducted by Multi-Tier Framework's (MTF) international initiative and that contain questions that are specifically tailored to collect data to assess energy access using the MTF measurement framework $(43,44)$. We also employ data from the Indian Human Development Survey (IHDS) II, which is a multi-topic survey conducted in 2011-12 covering questions on health, education, employment, expenditures, and income that also includes details on energy use

274 and housing conditions (45). We use this dataset for India to illustrate how general surveys, not specifically designed to collect MTF related data, can also be used to apply the framework. We use data on appliance ownership in the surveys to assign households across tiers of energy services as 
defined by the AF. Since the IHDS survey includes questions only on electricity expenditures and not on electricity consumption, we use another nationally representative survey dataset for India (the National Sample Survey Household Consumer Expenditure Survey Round 66) also conducted in 20112012 to estimate average electricity prices by quartiles of electricity use. The electricity expenditures in the IHDS survey are then divided by these quartile-specific average electricity prices to impute the implied electricity consumption. The imputed electricity consumption is used to assign households across tiers of electricity consumption as defined by the MTF.

To determine the assignment of households across electricity reliability or availability tiers in the MTF and $A F$, we use the question from the surveys on hours per day of electricity access. To determine the affordability dimension as specified in the MTF and AF, we determine the budget share of expenditures on electricity. For the proposed AF, we include in the electricity budget share, also the annualized discounted value of appliance costs. We use an annual discount rate of $10 \%$ to estimate the discounted values and source average lifetimes and appliance prices from the Euromonitor International consumer appliances and electronics database.

\subsection{A comparison of the frameworks}

The first thing to note from a comparison of the population distributions in all three countries across the MTF's six Tiers of electricity consumption and our 4 Tiers of electricity services is that consumption appears to be a poor proxy for access to energy services (Figure 2 (a)). Those defined as Tier 2 in Ethiopia and as Tier 3 in India under the MTF are distributed across all three tiers in the AF, indicating that these households enjoy very different levels of energy services. Yet, in the MTF, they would be considered as having the same energy poverty status. Similarly, households that fall in Tier 3 in Ethiopia and in Tier 4 in India fall are categorized as in 'decent' and 'affluent' tiers in the AF. Thus, some households that enjoy the same energy services, like 'decent' in the AF, fall into different tiers

301 in the MTF (Tier 2 and 3 in Ethiopia, or Tier 3 and Tier 4 in India). However, among those in our top 
tier of electricity service access, i.e. 'affluent', more than half are categorized as having less than Tier

3 electricity consumption access according to the MTF assignment. In other words, households that

enjoy a decent standard of living compared to most Indians, considering the energy services they

enjoy, are categorized as consuming only a mid-Tier level of electricity consumption according to the

MTF. In Rwanda, even among households in the 'affluent' tier of electricity service access as defined

in the AF, almost none are categorized as having more than Tier 2 electricity consumption access by

the MTF. In sum, it is clear that the categorization of households according to electricity consumption

differs markedly from that according to energy services and wellbeing. If the objective of such a categorization is to reflect heterogeneity in the distribution of enjoyed energy services, the AF would seem to be preferable.

According to the MTF's indicator and threshold of affordability (>5\%), practically no one in Ethiopia or India would be considered unable to afford electricity access (Figure 2(b)). However, if one considers in addition the discounted cost of appliances needed to consume electricity, about a fifth of households in India in the Improved tier shift to Basic in our framework (5-10\%). In this case, close to a third of the population in India and Ethiopia might be categorized as facing issues with affordability (spending $>5 \%$ of their budget on electricity services). In Rwanda, even without considering the discounted cost of appliances, most electricity consuming households spend more than even $10 \%$ of their budget on electricity.

Finally, we see that there is a strong overlap in the MTFs Tiers of availability/ reliability and those we define in our AF. The impact of fewer tiers is simply to collapse all households with greater than 16 hours of supply. We see no significant improvement in this regard with the AF other than simplicity. Applying either framework, it is evident that over half of the population in India and about a quarter of the population in Ethiopia receive less than 16 regular hours of electricity supply per day. Thus, reliability of electricity supply or regular availability is an issue that requires particular focus in these countries. The need for enhancing the quality of electricity supply has been emphasized by other 
327

328

329

330

331

332

333

334

335

336

337

\section{Discussion and conclusions}

Accurately characterizing what we mean by energy access and why we aim to improve it is important to the construction of new measurement frameworks and metrics for measuring it. Currently applied SDG indicators to track global progress towards Target 7.1 underestimate energy poverty and are inadequate to inform policies to improve access. Recognizing that access is neither binary nor unidimensional has led to the development of new measurement frameworks, such as the MTF, that are a significant improvement' over existing metrics. Yet, the MTF requires simplification and conceptual clarity for application on a global scale. The AF we propose here achieves this by pruning the dimensions to those specified in the stated SDG target, and defining thresholds to mark fewer tiers. We also distinguish between dimensions that characterize energy supply from those that relate 350 to household poverty. Furthermore, electricity consumption is a misleading indicator of electricity 
services. Instead, we suggest differentiating households based on the types of appliances they own, which reflect the contribution of electricity services to meeting or exceeding basic living standards. An application of our AF to Ethiopia, India and Rwanda suggests that there is greater heterogeneity among the energy poor than what is reflected by the MTF.

This AF is intended to be a starting point for developing an alternative energy poverty measurement framework. We have applied the proposed alternative to three countries. This is sufficient to demonstrate the limitations of the existing MTF framework but lends only limited support to our chosen thresholds. Application to other countries may reveal the need for greater granularity in tier definitions. The proposal also needs further refinements in conceptualization and its practicability. For example, affordability has been crudely measured, and the new thresholds (5-10\%) are relatively arbitrary. The number and thresholds of tranches should be determined based on further investigation of the relationship between electricity expenditure and the poor's overall budget for basic subsistence. Affordability also needs to consider cash flow constraints. We have partly accounted for this by including the upfront capital outlay for appliances, but households may face cash flow constraints even for monthly purchases. The AF also does not capture intra-household disparities in access.

The MTF distinguishes between and has separate matrices defined to measure access to (i) electricity, (ii) energy for cooking; (iii) energy for productive enterprises, and (iv) energy for community institutions. We define and apply the new AF here to assess access to household electric services alone. However, the AF can be similarly applied to assess access to energy for other purposes using the same underlying principles. Thus, access to energy for cooking, for instance, can be measured by making a similar distinction between dimensions that characterize energy supply from those that relate to household poverty. Aspects of energy supply to assess cooking energy access would require

374 distinguishing thresholds of reliability that may be measured in terms of time required for fuel collection (e.g. distance to LPG sales outlet, biomass source, etc.), as well as cost of supply. 
376 Characterizing aspects of household poverty that relate to access to cooking energy would require

377 applying a similar affordability indicator to measure the budget share spent on cooking. Tiers of energy

378 services relating to cooking energy might be defined on the basis of the stove and fuel combination a

379 household uses, accounting for the fact that households often use multiple fuels, and distinguishing

380 tiers by primary reliance on polluting stoves, a mix of polluting and clean-burning stoves, and primary

381 reliance on clean-burning stoves.

382 Further refinements and applications of the AF can help improve how we identify the most

383 vulnerable and design and target policies to improve energy access for all. Such efforts need to go

384 hand in hand with augmented and regular data collection. This is needed particularly in nations

385 where access is far from universal that typically suffer from the greatest data paucity too. These

386 might be through custom-designed surveys or enhancements to existing survey instruments. At

387 present, the new MTF surveys, which have been conducted in nine countries, collect data on all the

388 indicators required for application of the AF i.e. energy expenditures, hours of availability, and

389 appliance ownership. Future research might apply this new framework more widely to additional

390 countries, as the data from these surveys are released. Other existing national surveys, such as the

391 IHDS for India, also include data on the indicators needed to apply the AF. As mentioned earlier, the

392 World Bank and WHO are coordinating efforts to include a common set of questions on household

393 energy in other regular national surveys for monitoring SDG Indicators 7.1.1 \& 7.1.2. As new rounds

394 of these existing surveys, such as the DHS, MICS and LSMS, that incorporate this standardized set of

395 questions are completed, it will be possible to apply the AF more widely to multiple national

396 datasets. Exploring the use of other publicly available data sources, such as satellite-based earth

397 observations, and new ways of combining and processing these could also compliment analyses of

398 surveys $(46,47)$. New data gathering infrastructures need to also consider collecting information on

399 how progress on one pillar interconnects with the attainment of other sustainable development

400 objectives. Efforts in this direction can help ensure the inclusive and integrated spirit of the SDGs are

401 realized. 
402

403

404

405

406

407

408

409

410

411

412

413

414

415

416

417

418

419

420

421

422

423

424

425

426

427

428

429

430

\section{References}

1. UN. Transforming our world: The 2030 Agenda for Sustainable Development. Vol. A/RES/70/1, International Organization. New York: UN; 2015.

2. Sustainable Energy for All. Progress Toward Sustainable Energy 2015. Global tracking framework key findings [Internet]. 2015. Available from: http://www.worldbank.org/content/dam/Worldbank/Event/Energy and Extractives/Progress Toward Sustainable Energy - Global Tracking Framework 2015 - Key Findings.pdf

3. Pachauri S, Mueller A, Kemmler A, Spreng D. On measuring energy poverty in Indian households. World Dev. 2004;32(12).

4. Barnes DF, Khandker SR, Samad HA. Energy poverty in rural Bangladesh. Energy Policy. 2011 Feb;39(2):894-904.

5. Nussbaumer P, Bazilian M, Modi V. Measuring energy poverty: Focusing on what matters. Renew Sustain Energy Rev [Internet]. 2012 Jan 1 [cited 2019 Dec 20];16(1):231-43. Available from: https://www.sciencedirect.com/science/article/pii/S1364032111003972?via\%3Dihub

6. Trace S. Measuring access for different needs. 2015 Aug 20 [cited 2019 Dec 20];184-202. Available from:

https://www.taylorfrancis.com/books/e/9781315762203/chapters/10.4324/9781315762203 $-23$

7. Jain A, Urpelainen J, Stevens L, Jain A, Urpelainen J, Stevens L. Measuring Energy Access in India. In: Measuring Energy Access in India. Practical Action Publishing Ltd; 2016. p. 1-19.

8. Bazilian, M. et al. Measuring energy access: Supporting a global target. The Earth Institute, Columbia University;

9. Goldemberg J, Johansson TB, Reddy AKN, Williams RH. Basic needs and much more with one kilowatt per capita ( energy). Ambio. 1985;14(4-5):190-200.

10. Day R, Walker G, Simcock N. Conceptualising energy use and energy poverty using a capabilities framework. Energy Policy. 2016 Jun 1;93:255-64.

11. Samarakoon S. A justice and wellbeing centered framework for analysing energy poverty in the Global South. Ecol Econ [Internet]. 2019 Nov 1 [cited 2019 Dec 20];165:106385. Available from: https://www.sciencedirect.com/science/article/pii/S0921800919300461

431 12. Sen A. Inequality Reexamined [Internet]. Oxford University Press; 1995 [cited 2019 Dec 20]. 
432

433

434

435

436

437

438

439

440

441

442

443

444

445

446

447

448

449

450

451

452

453

454

455

456

457

458

459

460

461

Available from:

http://www.oxfordscholarship.com/view/10.1093/0198289286.001.0001/acprof9780198289289

13. Rawls J. A theory of justice. $538 \mathrm{p}$.

14. Sareen S, Saltelli A, Rommetveit K. Ethics of quantification: illumination, obfuscation and performative legitimation. Palgrave Commun [Internet]. 2020;6(1):1-5. Available from: http://dx.doi.org/10.1057/s41599-020-0396-5

15. Rao ND, Min J. Decent Living Standards: Material Prerequisites for Human Wellbeing. Soc Indic Res [Internet]. 2018 Jul 23 [cited 2019 Dec 20];138(1):225-44. Available from: http://link.springer.com/10.1007/s11205-017-1650-0

16. Pelke, M., Bazilian, M. and Roger J. Making Energy Access Meaningful [Internet]. Vol. 29, Issues in Science and Technology. University of Texas at Dallas; 2013 [cited 2019 Dec 20]. p. 74-8. Available from: https://www.jstor.org/stable/43315797

17. Sovacool BK, Cooper C, Bazilian M, Johnson K, Zoppo D, Clarke S, et al. What moves and works: Broadening the consideration of energy poverty. Energy Policy [Internet]. 2012 Mar 1 [cited 2019 Dec 20];42:715-9. Available from: https://www.sciencedirect.com/science/article/pii/S0301421511009992

18. Rao ND, Min J, Mastrucci A. Energy requirements for decent living in India, Brazil and South Africa. Nat Energy [Internet]. 2019 Dec 18 [cited 2019 Dec 20];4(12):1025-32. Available from: http://www.nature.com/articles/s41560-019-0497-9

19. Bensch G. Inside the Metrics-An Empirical Comparison of Energy Poverty Indices for SubSaharan Countries \#464 [Internet]. Available from: http://ssrn.com/abstract=2421306

20. Culver LC. Energy Poverty: What You Measure Matters.

21. Groh S, Pachauri S, Narasimha R. What are we measuring? An empirical analysis of household electricity access metrics in rural Bangladesh. Energy Sustain Dev. 2016;30.

22. Kowsari R. Three dimensional energy profile:: A conceptual framework for assessing household energy use. Energy Policy [Internet]. 2011 Dec 1 [cited 2019 Dec 20];39(12):750517. Available from: https://www.sciencedirect.com/science/article/pii/S0301421511004861

23. Pelz S, Pachauri S, Groh S. A critical review of modern approaches for multidimensional 
462

463

464

465

466

467

468

469

470

471

472

473

474

475

476

477

478

479

480

481

482

483

484

485

486

487

488

489

490

491

Available from: http://www.scopus.com/inward/record.url?eid=2-s2.085055280204\&partnerID=MN8TOARS

24. Ramde EW, Nussbaumer $\mathrm{P}$, Bazilian M. Measuring and reporting on energy poverty: insights from West African countries. African J Sci Technol Innov Dev [Internet]. 2015 Nov 2 [cited 2019 Dec 20];7(6):509-17. Available from:

http://www.tandfonline.com/doi/full/10.1080/20421338.2015.1094238

25. Nussbaumer P, Nerini F, Onyeji I, Howells M. Global Insights Based on the Multidimensional Energy Poverty Index (MEPI). Sustainability [Internet]. 2013 May 7 [cited 2019 Dec 20];5(5):2060-76. Available from: http://www.mdpi.com/2071-1050/5/5/2060

26. Bhatia M, Angelou N. Beyond connections - energy access redefined : technical report [Internet]. 2015 [cited 2019 Dec 20]. p. 1-244. Available from: http://documents.worldbank.org/curated/en/650971468180259602/Beyond-connectionsenergy-access-redefined-technical-report

27. Group WB. Harmonized survey questions for monitoring household energy use. 2019;(November):1-13.

28. Tait L. Towards a multidimensional framework for measuring household energy access: Application to South Africa. Energy Sustain Dev. 2017 Jun 1;38:1-9.

29. Aklin M, Cheng CY, Urpelainen J, Ganesan K, Jain A. Factors affecting household satisfaction with electricity supply in rural India. Nat Energy. 2016 Sep 19;1(11).

30. Monyei CG, Jenkins K, Serestina V, Adewumi AO. Examining energy sufficiency and energy mobility in the global south through the energy justice framework. Energy Policy [Internet]. 2018 Aug 1 [cited 2019 Dec 20];119:68-76. Available from: https://www.sciencedirect.com/science/article/pii/S030142151830243X?via\%3Dihub

31. Modi V, McDade S, Lallement D, Saghir J. Energy Services for the Millennium Development Goals. Progr Manag [Internet]. 2005;116. Available from: http://www.unmillenniumproject.org/documents/MP_Energy_Low_Res.pdf

32. AGECC. Energy for a Sustainable Future. The Secretary-General's Advisory Group on Energy and Climate Change. 2010. p. 44.

33. Practical Action. Poor people's energy outlook 2012 [Internet]. Warwickshire; 2012. Available from: http://cdn1.practicalaction.org/p/p/4f1ea5d5-024c-42a1-b88d-026b0ae4f5bb.pdf 
492

493

494

495

496

497

498

499

500

501

502

503

504

505

506

507

508

509

510

511

512

513

514

515

516

517

518

519

520

521

522

34. Blimpo MP, Cosgrove-Davies M. Electricity Access in Sub-Saharan Africa: Uptake, Reliability, and Complementary Factors for Economic Impact [Internet]. The World Bank; 2019 [cited 2019 Dec 20]. Available from: http://elibrary.worldbank.org/doi/book/10.1596/978-1-4648$1361-0$

35. Graber S, Narayanan T, Alfaro J, Palit D. Solar microgrids in rural India: Consumers' willingness to pay for attributes of electricity. Energy Sustain Dev [Internet]. 2018 Feb 1 [cited 2019 Dec 20];42:32-43. Available from:

https://www.sciencedirect.com/science/article/pii/S0973082617307615?via\%3Dihub

36. Rao ND. Does (better) electricity supply increase household enterprise income in India? Energy Policy [Internet]. 2013 Jun 1 [cited 2019 Dec 20];57:532-41. Available from: https://www.sciencedirect.com/science/article/pii/S0301421513001109?via\%3Dihub

37. Kooijman-van Dijk AL. The role of energy in creating opportunities for income generation in the Indian Himalayas. Energy Policy [Internet]. 2012 Feb 1 [cited 2019 Dec 20];41:529-36. Available from: https://www.sciencedirect.com/science/article/pii/S0301421511008901

38. Thomson H, Bouzarovski S, Snell C. Rethinking the measurement of energy poverty in Europe: A critical analysis of indicators and data. Indoor Built Environ. 2017 Aug 1;26(7):879-901.

39. Rao ND, Ummel K. White goods for white people?,Drivers of electric appliance growth in emerging economies. Energy Res Soc Sci [Internet]. 2017 May 1 [cited 2019 Dec 20];27:10616. Available from: https://www.sciencedirect.com/science/article/pii/S2214629617300750

40. Ormandy D, Ezratty V. Health and thermal comfort: From WHO guidance to housing strategies. Energy Policy. 2012;49:116-21.

41. Mastrucci A, Byers E, Pachauri S, Rao ND. Improving the SDG energy poverty targets: Residential cooling needs in the Global South. Energy Build [Internet]. 2019 Mar; Available from: https://doi.org/10.1016/j.enbuild.2019.01.015

42. Sustainable T, For C. CHILLING PROSPECTS :

43. World Bank. Ethiopia -Multi-Tier Framework (MTF) Survey | Data Catalog [Internet]. [cited 2019 Dec 20]. Available from: https://datacatalog.worldbank.org/dataset/ethiopia-multi-tierframework-mtf-survey-2018

44. World Bank. Rwanda - Multi-Tier Framework (MTF) Survey | Data Catalog [Internet]. [cited 2019 Dec 20]. Available from: https://datacatalog.worldbank.org/dataset/rwanda-multi-tierframework-mtf-survey-2018 
523 45. Desai S, Vanneman R, National Council of Applied Economic Research ND. India Human Development Survey (IHDS), 2005. Inter-university Consortium for Political and Social Research [distributor]; 2018.

526

46. Falchetta G, Pachauri S, Parkinson S, Byers E. A high-resolution gridded dataset to assesS electrification in sub-Saharan Africa. Sci Data [Internet]. 2019 Dec 3 [cited 2019 Dec 20];6(1):110. Available from: http://www.nature.com/articles/s41597-019-0122-6

529 47. Falchetta G, Pachauri S, Byers E, Danylo O, Parkinson SC. Satellite Observations Reveal Inequalities in the Progress and Effectiveness of Recent Electrification in Sub-Saharan Africa.

$531 \quad$ One Earth. 2020;2(4):364-79.

532 


\begin{tabular}{|c|c|c|c|c|c|c|c|c|c|c|c|}
\hline \multicolumn{12}{|c|}{\begin{tabular}{|l|l|l|l|} 
AF Measurement of Household Access to Electric Services & MTF Measurement of Household Access to Electric Services*
\end{tabular}} \\
\hline & Tier 0 & Tier 1 & $\mathrm{Ti}$ & Tier 3 & & Tier 0 & Tier 1 & Tier 2 & Tier 3 & Tier 4 & Tier 5 \\
\hline \multicolumn{5}{|c|}{ Energy Supply Poverty } & & & & & & & \\
\hline Availability & None & $<8 \mathrm{hrs}$ & 8-16 & $>16 \mathrm{hrs}$ & $\begin{array}{l}\text { Duration- } \\
\text { Day } \\
\text { Evening }\end{array}$ & & $\geq 4 \mathrm{hrs}$ & $\geq 4 \mathrm{hrs}$ & $\geq 8 \mathrm{hrs}$ & $\begin{array}{l}\geq 16 \mathrm{hrs} \\
\geq 4 \mathrm{hrs}\end{array}$ & $\begin{array}{l}\geq 23 \mathrm{hrs} \\
\geq 4 \mathrm{hrs}\end{array}$ \\
\hline $\begin{array}{l}\text { Cost of } \\
\text { supply^ }\end{array}$ & NA & NA & & NA & Quality & & & & & \multicolumn{2}{|c|}{$\begin{array}{l}\text { Voltage problems do not } \\
\text { affect use of desired } \\
\text { appliances }\end{array}$} \\
\hline \multicolumn{5}{|c|}{ Energy Service Poverty } & $\begin{array}{l}\text { Reliability } \\
\text { Disruptions } \\
\text { per week }\end{array}$ & & & & & $\leq 14$ & $\begin{array}{c}\leq 3 \text { of total } \\
\text { duration }<2 \mathrm{hrs}\end{array}$ \\
\hline \multirow[t]{2}{*}{ Service level } & None & $\begin{array}{l}\text { Minimal } \\
\text { (Lighting } \\
\text { phone } \\
\text { charging) }\end{array}$ & $\begin{array}{l}\text { Decent } \\
+ \text { (TV | } \\
\text { fridge| } \\
\text { cooling) }\end{array}$ & $\begin{array}{l}\text { Affluent } \\
+ \text { (other } \\
\text { appliances } \\
\text { ) }\end{array}$ & Capacity & & $\geq 3 W$ & $\geq 50 \mathrm{~W}$ & $\geq 200 \mathrm{~W}$ & $\geq 800 \mathrm{~W}$ & $\geq 2 \mathrm{~kW}$ \\
\hline & & & & & $\begin{array}{l}\text { Consumption } \\
\text { levels, in } \\
\text { Wh/day }\end{array}$ & $<12$ & $\geq 12$ & $\geq 200$ & $\geq 1,000$ & $\geq 3,425$ & $\geq 8,219$ \\
\hline $\begin{array}{l}\text { Affordability } \\
\text { (budget share }\end{array}$ & & $>10 \%$ & $5-10 \%$ & $<5 \%$ & Affordability & & & & \multicolumn{3}{|c|}{$\begin{array}{l}\text { Cost of standard consumption } \\
\text { package of } 365 \mathrm{kWh} \text { per annum is }< \\
\text { than } 5 \% \text { of household income }\end{array}$} \\
\hline
\end{tabular}




\section{Figure 2}
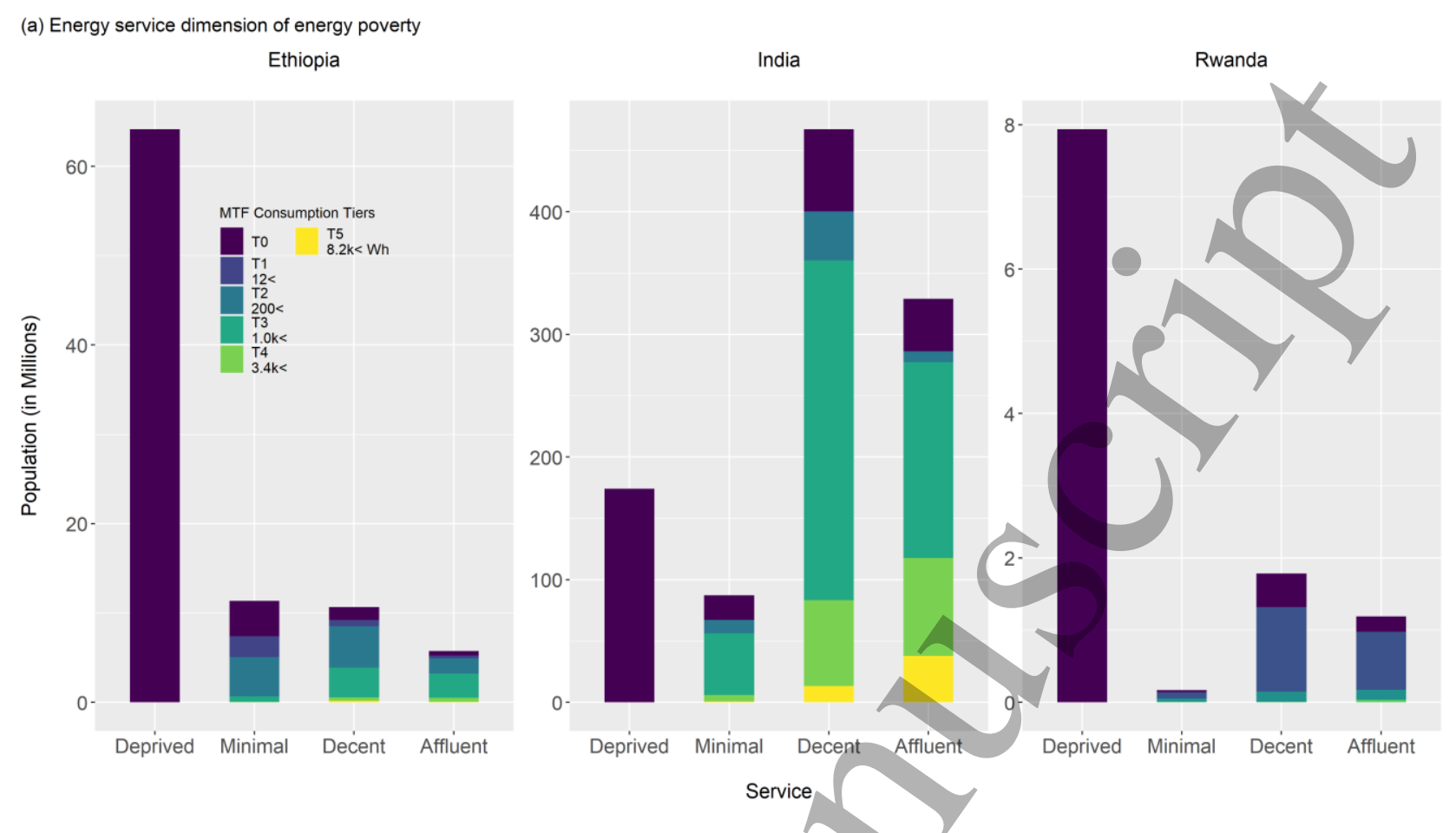

538 
(b) Affordability dimension of energy poverty

Ethiopia

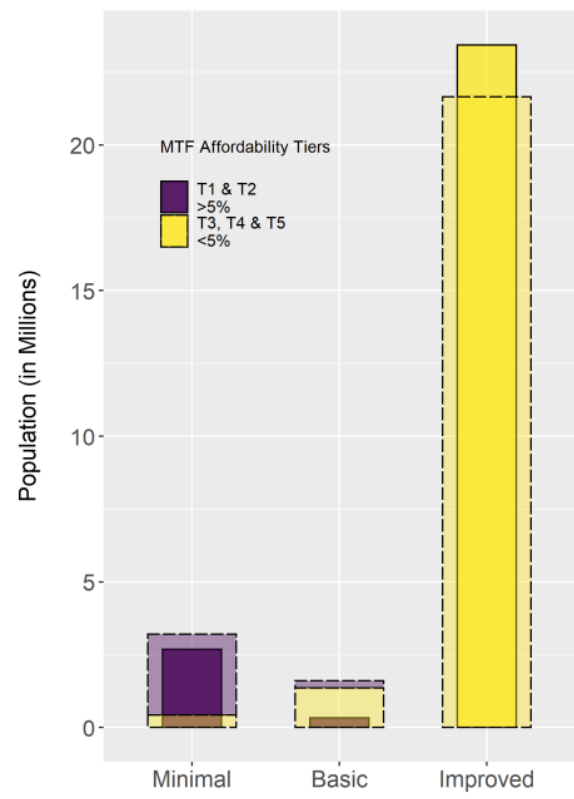

539

(c)Reliability/Availability dimension of electricity supply Ethiopia

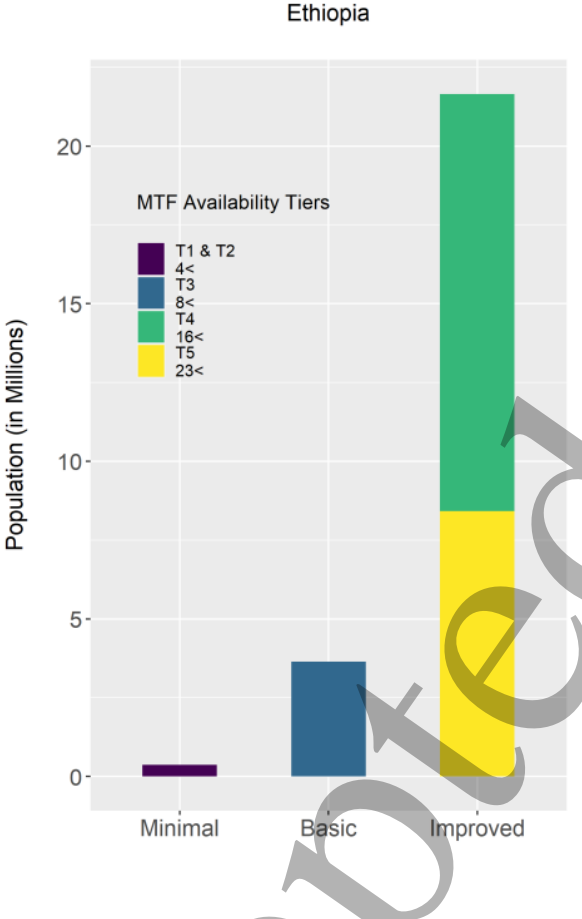

540

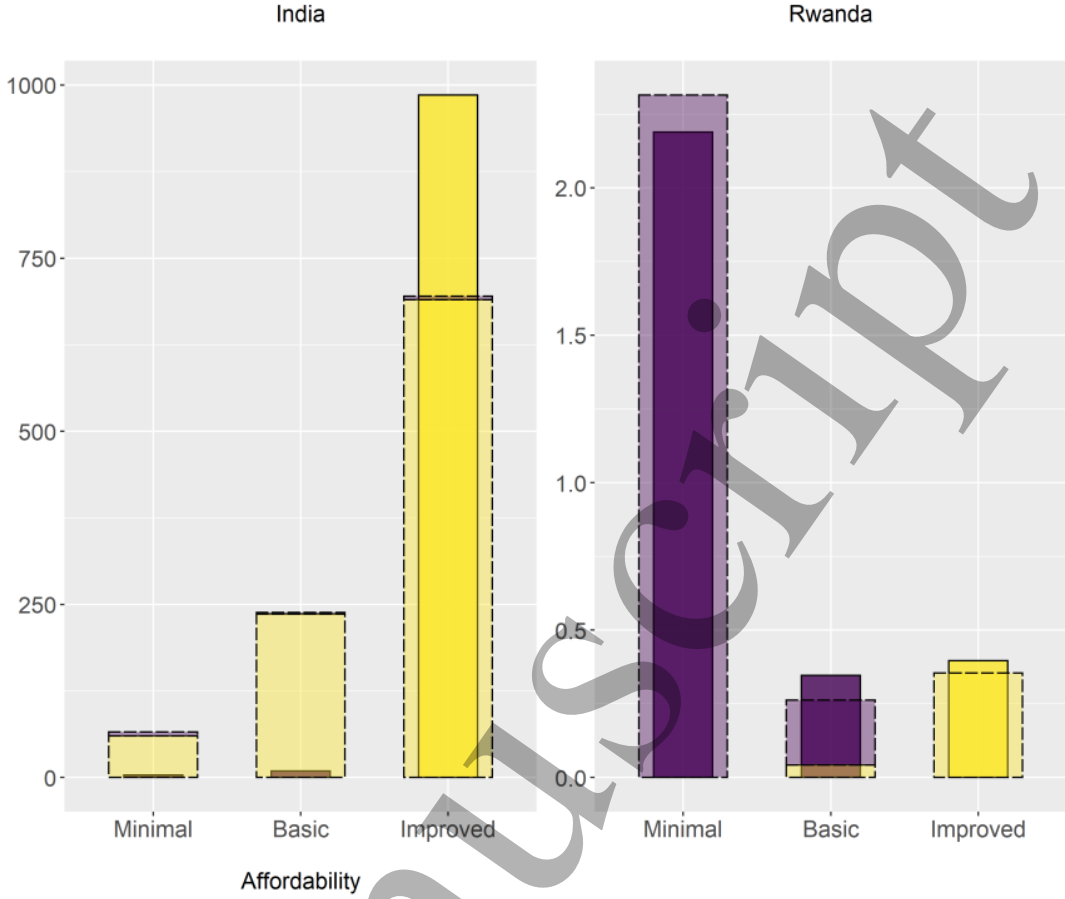

Rwanda
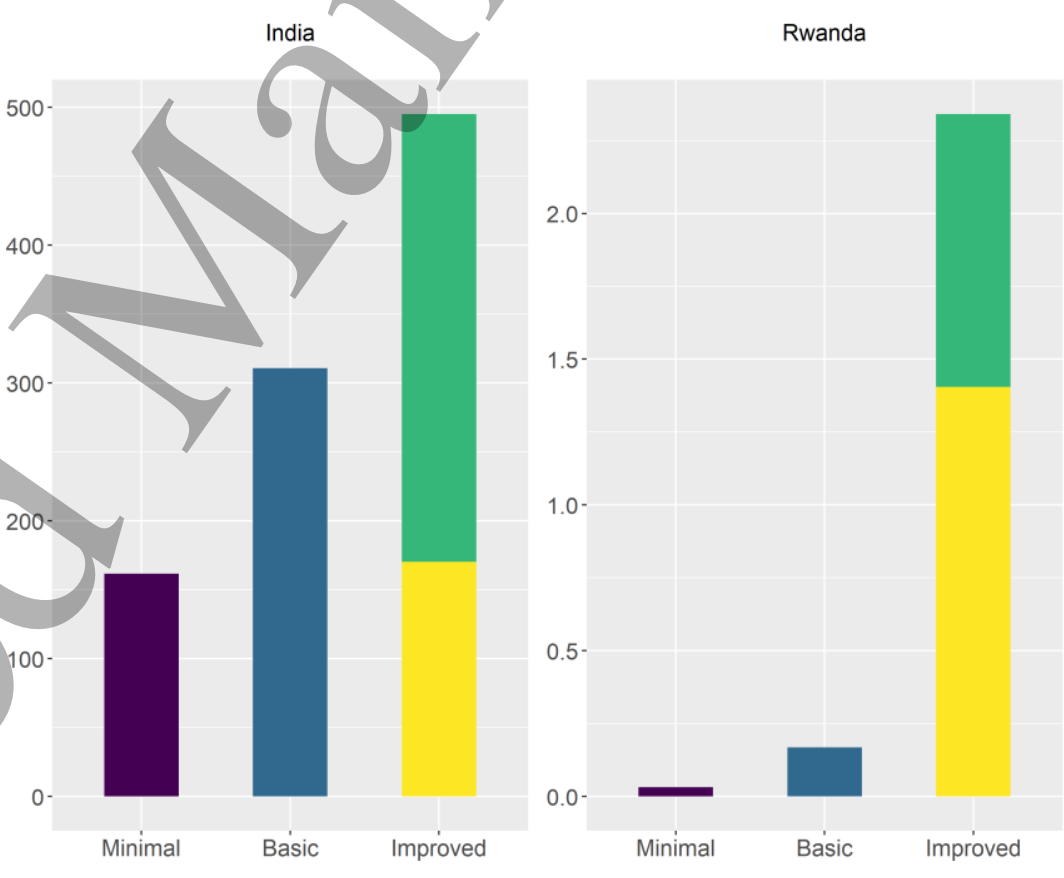

$1.5-$

1.0

$200-1-1-2$

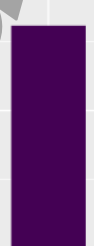

Availability 